\title{
Ambiente térmico e concentração de gases em instalações para frangos de corte no período de aquecimento ${ }^{1}$
}

Irene Menegali'2, Ilda de F. F. Tinôco ${ }^{2}$, Fernando da C. Baêta ${ }^{2}$, Paulo R. Cecon ${ }^{3}$, Maria C. de C. G uimarães ${ }^{2} \&$ Marcelo B. Cordeiro ${ }^{2}$

RESUMO

Atualmente, demandas do mercado nacional e internacional pregam, em geral, ações voltadas, sobretudo para a preservação ambiental, incluindo os levantamentos de dados de concentração ou emissão de gases nocivos, gerados pela atividade de produção animal. 0 tema ainda é pal pitante para as condições do Brasil, devido à carência de informações, razão por que se objetivou, com este trabalho, diagnosticar as concentrações de monóxido e dióxido de carbono, associadas ao conforto térmico em gal pões de frango de corte na fase de aquecimento e submetidos a dois diferentes sistemas de acondicionamento de renovação de ar: ventilação por pressão negativa e por pressão positiva, em condições de inverno, na região sul do Brasil. Para avaliação do ambiente térmico val eu-se do delineamento em bloco casualizado, em parcelas subdivididas, com 2 repetições. 0 índice de temperatura de globo negro e umidade indicou as melhores condições de conforto térmico ambiente na primeira semana de vida das aves para o tratamento por pressão positiva. As maiores concentrações gasosas foram detectadas no período da manhã, nos dois tratamentos, com concentrações de $\mathrm{CO}$ e $\mathrm{CO}_{2}$ dentro dos limites aceitáveis para o bom desenvolvimento do plantel.

Palavras-chave: conforto térmico, monóxido de carbono, dióxido de carbono, produção de frangos de corte

\section{Thermal environment and gas concentrations in poultry houses during heating}

\begin{abstract}
Currently, the national and international markets are stressing actions for environmental preservation, including data collection regarding concentrations or emission of harmful gases generated from animal production. The lack of information regarding this subject is the reason for this study which is to diagnose the concentrations of carbon monoxide and carbon dioxide associated with the thermal comfort of broiler chickens in poultry houses. Two different types of air renovation for heating were studied: ventilation by negative pressure and by positive pressure, during winter in the southern region of Brazil. For evaluation of the thermal environment, randomized blocks were used in split-plot design with two repetitions. The index of the black globe's temperature and humidity indicated the best conditions for thermal comfort environment in the first week of the life of the birds for positive pressure of the system. The highest gas concentrations were detected in the morning for both air renovation methods, with concentrations within the acceptable levels for good bird development.
\end{abstract}

Key words: thermal comfort, carbon monoxide, carbon dioxide, broiler production

1 Parte da Dissertação de Mestrado do primeiro autor, financiada pela CAPES/UFV

${ }^{2}$ Departamento de Engenharia Agrícola, AMBIAGRO/UFV, Avenida P.H. Rolfs s/n, CEP 36570-000, Campus U FV, Viçosa, M G. Fone: (31) 3899-1865. E-mail: imenegali@yahoo.com.br; iftinoco@ufv.br; baeta@ufv.br; mclaracg@yahoo.com.br; mb_cordeiro@yahoo.com.br

${ }^{3}$ Departamento de Estatística/U FV, Fone: (31) 3899-1781. E-mail: cecon@dpi.ufv.br 


\section{INTRODUÇÃO}

Os volumes de produção e exportação atingidos nos últimos anos destacaram a avicultura brasileira, tanto pela geração de renda ao meio rural, quanto pela oferta à população de uma proteína de alta qualidade e sanidade. Segundo o relatório anual da União Brasileira de Avicultura (UBA, 2008), em 2007 a avicultura obteve novos recordes no mercado de exportação, com embarques de 3,3 milhões de toneladas, mantendo o Brasil na posição de maior exportador mundial.

Nas últimas duas décadas, segundo Tinôco (2001) a indústria avícola brasileira, adicionalmente aos antigos investimentos já realizados em genética, nutrição e manejo, passou também a buscar nas instalações e no ambiente as possibilidades de melhoria no desempenho das aves e redução de custos de produção, como forma de manter a competitividade.

Dentre os fatores do ambiente, os térmicos são os que afetam mais diretamente a ave, pois comprometem sua função vital mais significativa, que é a manutenção de sua homeotermia, e nas fases iniciais de vida o fornecimento de calor para as aves é essencial, quando existe risco de estresse por frio (Tinôco, 2001).

Em períodos frios é necessário evitar perda de calor para fora do aviário; portanto, o controle das aberturas é de fundamental importância. Por outro lado, a ventilação apresenta função relevante, principalmente por razões higiênicas, fazendo-se a renovação do ar para evitar concentrações de gases indesejáveis dentro do aviário (Tinôco, 2001; Nääs et al., 2007).

Atualmente se usa como isolamento, a formação de zonas de conforto térmico temporário para os primeiros dias, ou seja, o tradicional sistema de pinteiros tipo estufa, instalados com cortinas plastificadas, que restringem determinada área do galpão para criação dos pintinhos, reduzindo a área a ser aquecida (Silva \& Nääs, 2004).

A umidade relativa passa a ter grande significado no conforto térmico das aves, quando a temperatura ambiental atinge $25^{\circ} \mathrm{C}$; na fase inicial de aquecimento dos frangos são comuns níveis abaixo de $40 \%$ de umidade relativa, pois o excesso de calor fornecido pelos aquecedores consome o oxigênio do ambiente, reduzindo muito a umidade relativa na altura das campânulas, além de favorecer a dispersão de vírus e bactérias em razão do aumento da concentração de poeiras (Moura, 2001).

O índice de temperatura de globo negro e umidade (ITGU), proposto por Buffington et al. (1981), é considerado mais adequado na avaliação do ambiente térmico em condições de climas tropicais. Este índice considera, em um único valor, os efeitos da temperatura de bulbo seco, da umidade relativa, da radiação e da velocidade do ar.

Um componente extremamente relevante para produção avícola é a qualidade do ar. Os poluentes aéreos, quando alteram as características ideais do ar, favorecem o aumento da susceptibilidade a doenças respiratórias e prejuízos no processo produtivo (Alencar et al., 2004; Nääs et al., 2007).

As trocas de ar inadequadas aumentam as concentrações de partículas de monóxido de carbono (CO), dióxido de carbono $\left(\mathrm{CO}_{2}\right)$, e amônia $\left(\mathrm{NH}_{3}\right)$ no interior das instalações, diminuindo as concentrações de oxigênio $\left(\mathrm{O}_{2}\right)$ favorecendo, as- sim, a incidência de ascite em aves de corte (Alencar et al., 2004; Owada et al., 2007). Alguns sistemas de aquecimento consomem o $\mathrm{O}_{2}$ no interior das instalações aumentando a concentração do gás $\mathrm{CO}_{2}$ em especial em ambientes mal ventilados. Como o $\mathrm{CO}_{2}$ é mais denso que o ar e é oriundo principalmente da respiração dos animais e de aquecedores, sua tendência é permanecer no nível das aves, dificultando a atividade respiratória e causando abatimento (Ronchi, 2004).

Níveis de $\mathrm{CO}_{2}$ superiores a $1,2 \%$ causaram efeitos negativos em pintos e frangos, como ofegação, anóxia, redução do consumo de ração e redução do crescimento (Reece et al., 1980). Para instalações avícolas, Wathes (1999) recomenda o limite de 3.000 ppm para $\mathrm{CO}_{2}$ como o máximo para exposição contínua dos animais nas instalações.

O monóxido de carbono, levemente menos denso que o ar, é inodoro e, em geral, tem sua concentração aumentada em uma instalação animal a partir da combustão incompleta de um combustível, devido a falhas no ajuste dos aquecedores utilizados, juntamente com ventilação inadequada do ambiente. Wathes (1999) recomenda o limite de 10 ppm para CO, como o máximo para exposição contínua dos animais nas instalações; desta forma, uma instalação avícola ideal, em termos de conforto térmico para as aves e consequente boa qualidade do ar, prevê uma circulação de ar que se ajuste à finalidade de remover o excesso de umidade e calor concentrado no interior dos galpões. Mesmo nos meses mais frios, quando se deseja manter a temperatura interna do aviário em níveis adequados à sobrevivência e produtividade do lote, a função da ventilação seria renovar o ar interno, controlando a concentração de gases, poeira e vapor de água produzido (Nääs et al., 2001).

O levantamento das condições de qualidade do ar em cada um dos sistemas de ventilação adotados pela avicultura brasileira, para cada uma das diferentes regiões e estações climáticas do país, é uma necessidade imperativa e urgente das indústrias de produção animal disponibilizando, com isto, dados de interesse a um inventário nacional, constituindo parte de banco de dados em concentração de gases nocivos pela referida atividade em atendimento das demandas internacionais do mercado, visando à exportação e ao atendimento das leis de preservação ambiental.

O trabalho foi realizado com o objetivo de diagnosticar e analisar a qualidade do ar em relação às concentrações de monóxido e dióxido de carbono, e o ambiente térmico (avaliado pela umidade relativa do ar e pelo índice de temperatura de globo negro e umidade), no período de aquecimento, na criação de frangos de corte em aviários semi-climatizados, com dois diferentes sistemas de acondicionamento, ventilação por pressão negativa e por pressão positiva, em condições de inverno, na região sul do Brasil.

\section{MATERIAL E MÉTODOS}

O experimento foi conduzido durante os meses de julho a setembro de 2004, em instalações avícolas comerciais integradas, no município de Videira, região Oeste de Santa Catarina, 
cujas coordenadas geográficas são latitude $27^{\circ} 00^{\prime} 30^{\prime \prime}$ Sul e longitude $51^{\circ} 09^{\prime}$ 06" Oeste e $750 \mathrm{~m}$ de altitude.

O clima da região é do tipo temperado úmido, com as estações bem definidas apresentando temperatura média anual de $17,1^{\circ} \mathrm{C}$, com variação média de $20^{\circ} \mathrm{C}$ no verão e $11^{\circ} \mathrm{C}$ no inverno.

Conduziu-se o ensaio em duas instalações de um mesmo setor de produção, disponibilizados para criação de fêmeas leves para fins de exportação, posicionados lado a lado, com seus eixos longitudinais orientados no sentido Leste-Oeste, nas dimensões de $100 \times 12 \mathrm{~m}$, pé-direito de $2,80 \mathrm{~m}$, totalizando uma área de $1200 \mathrm{~m}^{2}$ cada uma; as duas instalações possuíam diferentes sistemas de acondicionamento ambiente, constituindo: a) sistema de ventilação por pressão negativa (SVN), com estrutura de cobertura metálica com telhas de zinco; b) sistema de ventilação por pressão positiva (SVP), com estrutura de cobertura com telhas de barro.

As aves eram da linhagem $\mathrm{COBB}^{\circledR}$ (fêmeas leves para exportação), com distribuição de 24.500 pintinhos no aviário com sistema de ventilação por pressão negativa (SVN) e densidade de 20,4 pintinhos por $\mathrm{m}^{2}$ e de 17.650 pintinhos no aviário com ventilação por pressão positiva (SVP) com densidade de 14,7 pintinhos por $\mathrm{m}^{2}$.

Ambas as instalações foram equipadas com sistema de aquecimento a gás, constituído por campânulas infravermelhas, posicionadas a $1,10 \mathrm{~m}$ de altura da cama, fazendo um ângulo de $45^{\circ}$ com o plano horizontal, distribuídas alternadamente, visando a uma uniformidade melhor no aquecimento do pinteiro. Cada campânula possuía capacidade de aquecimento para cada 1.200 pintinhos, com acionamento realizado através de termostatos instalados próximo às mesmas e no nível das aves, visando acompanhar as exigências ambientais dos pintinhos.

Na primeira semana de vida das aves a temperatura para acionamento das campânulas ocorria quando da incidência de temperatura em níveis $<32^{\circ} \mathrm{C}$, e o desligamento do sistema com verificação de temperatura $>34^{\circ} \mathrm{C}$; para a segunda semana de vida das aves o acionamento foi com temperaturas $<28^{\circ} \mathrm{C}$, e desligamento ao se obter temperaturas $>32^{\circ} \mathrm{C}$.

As práticas de manejo das aves seguiram as orientações técnicas habitualmente utilizadas pela empresa, incluindo densidades de alojamento, manejo de abertura de cortinas conforme a necessidade, dentre outras. A coleta de dados experimentais compreendeu dois lotes de criação sucessivos, correspondentes ao tempo de aquecimento interno das instalações no período produtivo.

No sistema de ventilação positiva (SVP) a ventilação higiênica do ar no período de aquecimento, foi feita apenas pelo manejo de abertura de cortinas, como é usual no Brasil. Usouse, no sistema de ventilação negativa $(\mathrm{SVN})$ um exaustor com vazão de $560 \mathrm{~m}^{3}$ por min, automatizado com temporizadores, timer liga e desliga.

Com a finalidade de caracterizar o ar no interior dos galpões realizaram-se medições de concentração de dióxido de carbono e monóxido de carbono (nas duas primeiras semanas - fase de aquecimento), em ppm, no nível das aves $(0,30$ $\mathrm{m}$, ou seja, aproximadamente à altura de sua respiração); as medições foram feitas em um ponto central em relação ao comprimento de cada instalação, ás 9 e 15 h.

Utilizaram-se sensores para detectar a concentração instantânea dos gases mencionados; para o $\mathrm{CO}_{2} \mathrm{o}$ sensor foi da marca Testo, modelo 535, de princípio infravermelho, com resolução de 1 ppm e acurácia de \pm 50 ppm, que detecta a concentração instantânea, em uma faixa de medição de 0 a 10.000 ppm. Para a coleta de dados de $\mathrm{CO}$, usou-se sensor da marca Testo, modelo 315-2, de princípio eletroquímico, com resolução de 1 ppm e acurácia de \pm 1 ppm que detecta a concentração instantânea em uma faixa de medição de 0 a 100 ppm. Visando garantir a precisão das leituras fez-se, previamente, a calibração dos equipamentos utilizando-se gases de calibração-padrão (White Martins ${ }^{\circledR}$ ).

Continuamente, realizaram-se medições das variáveis ambientais e, no ambiente interno, se realizaram coleta de dados de temperatura do ar, umidade relativa do ar e temperatura de globo negro, enquanto no ambiente externo, a coleta de dados de temperatura do ar e umidade relativa do ar. Os instrumentos foram instalados em três pontos eqüidistantes ao longo do comprimento de cada instalação; todos os instrumentos foram posicionados a uma altura de $0,30 \mathrm{~m}$ do piso no ambiente interno e, para os dados climáticos do ambiente externo, utilizou-se um abrigo meteorológico, instalado nas proximidades das instalações, a uma altura aproximada de 1,5 m e com a frente voltada para a face sul. Os registros foram realizados com o uso de dataloggers de leitura contínua em intervalo de 15 min, durante todo o período experimental, totalizando 96 horários de coleta por dia, composto de dois ciclos produtivos para fêmeas leves; desses dados se calcularam os índices de temperatura de globo negro e umidade (ITGU); embora seja considerado um dos índices mais confiáveis na avaliação do conforto térmico em condições de clima tropical, o dado de temperatura de globo negro (Tgn) não é obtido pelas estações climatológicas, como rotina impossibilitando, muitas vezes, o uso do referido índice o qual com base na equação de Buffington et al. (1981), pode ser obtido por meio da Eq. 1:

$$
\mathrm{ITGU}=\text { Tgn }+0,36 * \text { Tpo }+41,7
$$

em que:

Tgn - temperatura de globo negro, ${ }^{\circ} \mathrm{C}$

Tpo - temperatura do ponto de orvalho, ${ }^{\circ} \mathrm{C}$

Nas duas primeiras semanas de vida as aves foram manejadas em sistemas de pinteiros, período em que receberam aquecimento suplementar. A densidade na primeira semana para o SVP foi de 52 aves $\mathrm{m}^{-2}$ e de 62 aves $\mathrm{m}^{-2}$ no SVN, com expansão sucessiva dessas áreas até a segunda semana, em um incremento de $2 \mathrm{~m}$ no sentido do comprimento da instalação a cada dois dias, conforme necessidade, e a medida em que ocorria o crescimento das aves.

Para efeito de análise estatística, a avaliação dos gases se deu por meio de esquema fatorial 2 x 2 no delineamento em blocos casualizados, com 14 repetições para as variáveis $\mathrm{CO}_{2}$ e CO.

Para a avaliação do ambiente térmico (umidade relativa e ITGU) o experimento se deu disposto segundo um esquema 
de parcelas subdivididas tendo, nas parcelas, os tratamentos (semi-climatizados com sistema de ventilação por pressão negativa e sistema de ventilação por pressão positiva) e, nas subparcelas, os tempos (96 horários) no delineamento em blocos casualizados com 2 repetições (correspondentes aos períodos de produção).

Os dados foram analisados por meio de análise de variância e de regressão. Para o fator quantitativo, os modelos foram escolhidos com base na significância dos coeficientes de regressão utilizando-se o teste "t" e se adotando o nível de 5\% de probabilidade, no coeficiente de determinação e no fenômeno biológico; para o fator qualitativo as médias foram comparadas por meio do teste F e se adotando o nível de $5 \%$ de probabilidade.

\section{RESULTADOS E DISCUSSÃO}

\section{Temperatura do ar ambiente}

A Figura 1 apresenta os resultados médios de temperatura do ar (Ta), observados nos ambientes interno e externo, referentes às primeira e segunda semanas de vida das aves, correspondentes aos dois tratamentos de ventilação higiênica do ar no período de aquecimento, SVN e SVP.

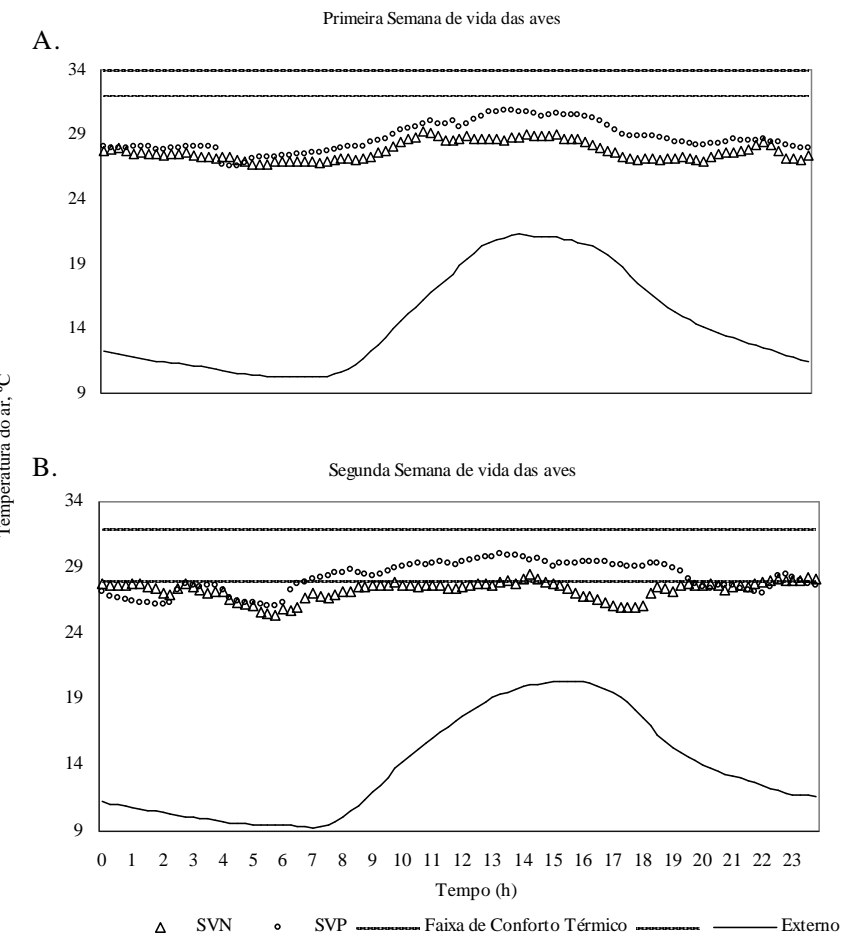

Figura 1. M édia da temperatura do ar ( $\mathrm{Ta})$, no ambiente interno e externo, em função dos horários, para a primeira semana de vida das aves (A), e para a segunda semana de vida das aves (B), correspondentes aos tratamentos com Sistema de ventilação com pressão negativa (SVN) e positiva (SVP), respectivamente

A faixa ideal para o conforto térmico para a primeira semana de vida das aves encontra-se entre 32 e $34{ }^{\circ} \mathrm{C}$ e para a segunda entre 28 e $32{ }^{\circ} \mathrm{C}$ (Oliveira et al., 2006). Observase, pela Figura 1A, que o comportamento da temperatura, para os dois tratamentos, foi semelhante, em que os menores valores observados foram em torno de $5 \mathrm{~h}$ e os maiores entre 11 e $16 \mathrm{~h}$.

Verifica-se, de forma geral que, independente do tratamento (SVN e SVP), as médias de temperatura correspondentes à primeira semana de vida das aves estiveram sempre abaixo da faixa ideal da zona de conforto térmico, ou seja, apresentaram-se entre 26,57 e $30,91{ }^{\circ} \mathrm{C}$.

Conforme a Figura 1B, os menores valores médios de Ta observados para a segunda semana, em ambos os tratamentos se mantiveram entre 5 e $6 \mathrm{~h}$, sendo que somente no SVP se atingiu a faixa ideal para o conforto térmico exigido pelas aves e apenas entre 7, 19, 22 e 23 h. Nos demais horários no SVP e em todos os horários no SVN, os valores de T foram inferiores aos desejados, indicando problemas no sistema de aquecimento das aves e má vedação das laterais das instalações, dentre outros.

Ressalta-se que na primeira e segunda semana de alojamento (primeiros 14 dias), quando se exigem valores de temperaturas acima de $28{ }^{\circ} \mathrm{C}$, para que os pintinhos se devolvam de maneira satisfatória, fontes suplementares de calor lhes foram fornecidas, através de campânulas infravermelhas.

Mesmo com o aquecimento na primeira semana não se conseguiu atingir os níveis ótimos de temperatura do ar, fato que se deve ao inverno muito rigoroso que incide na região sul do Brasil e, ainda, pelas possíveis falhas de manutenção nos sistemas de aquecimento fazendo com que os mesmos não alcançassem a máxima eficiência necessária.

\section{Índices do ambiente térmico}

Apresentam-se, na Tabela 1, as equações de regressão ajustadas para a umidade relativa do ar (UR) e índice de temperatura de globo e umidade (ITGU), em função dos horários, e seus respectivos coeficientes de determinação.

Tabela 1. Equações de regressão ajustadas para umidade relativa do ar (UR) e índice de temperatura de globo e umidade (ITGU), em função das horas observadas, e respectivos coeficientes de determinação $\left(R^{2}\right)$ para a fase de aquecimento

\begin{tabular}{|c|c|c|c|c|c|}
\hline Sem. & Trat & Umidade Relativa & $\begin{array}{c}R^{2} \\
\text { (UR) }\end{array}$ & ITGU & $\begin{array}{c}R^{2} \\
\text { (ITGU) }\end{array}$ \\
\hline \multirow[b]{2}{*}{$1^{\underline{a}}$} & SVN & $\hat{U R}=\bar{x}=64,79 \%$ & - & ITGU $=\bar{x}=80,16$ & - \\
\hline & SVP & $65,85 \%$ & & $\begin{array}{l}\text { ITGU }=76,86-0,0117 * H+ \\
0,00003^{*} * H^{2}-0,00000001 * * H^{3}\end{array}$ & 0,74 \\
\hline \multirow[b]{2}{*}{$2^{\underline{a}}$} & SVN & $\hat{U R}=\bar{x}=76,16 \%$ & - & ITGU $=\bar{x}=87,44$ & - \\
\hline & SVP & $\begin{array}{c}\mathrm{R}=75,86+0,0120^{\text {n.s }} \mathrm{H} \\
-0,00004^{* *} \mathrm{H}^{2}+ \\
0,00000002^{* *} \mathrm{H}^{3}\end{array}$ & 0,53 & $\begin{aligned} \text { ITGU }= & 74,09+0,0115 * * H- \\
& 0,0000006^{* *} H^{2}\end{aligned}$ & 0,70 \\
\hline
\end{tabular}

\footnotetext{
** significativo a nível de $1 \%$ de probabilidade, pelo teste T; * significativo a nível de $5 \%$ de probabilidade, pelo teste T; n.s não significativo
}

Na Figura 2 apresenta-se os resultados médios de umidade relativa do ar (UR), observados nos ambientes interno e externo, referentes a primeira e segunda semanas de vida das aves, correspondentes aos dois tratamentos de ventilação higiênica do ar no período de aquecimento, SVN e SVP. 


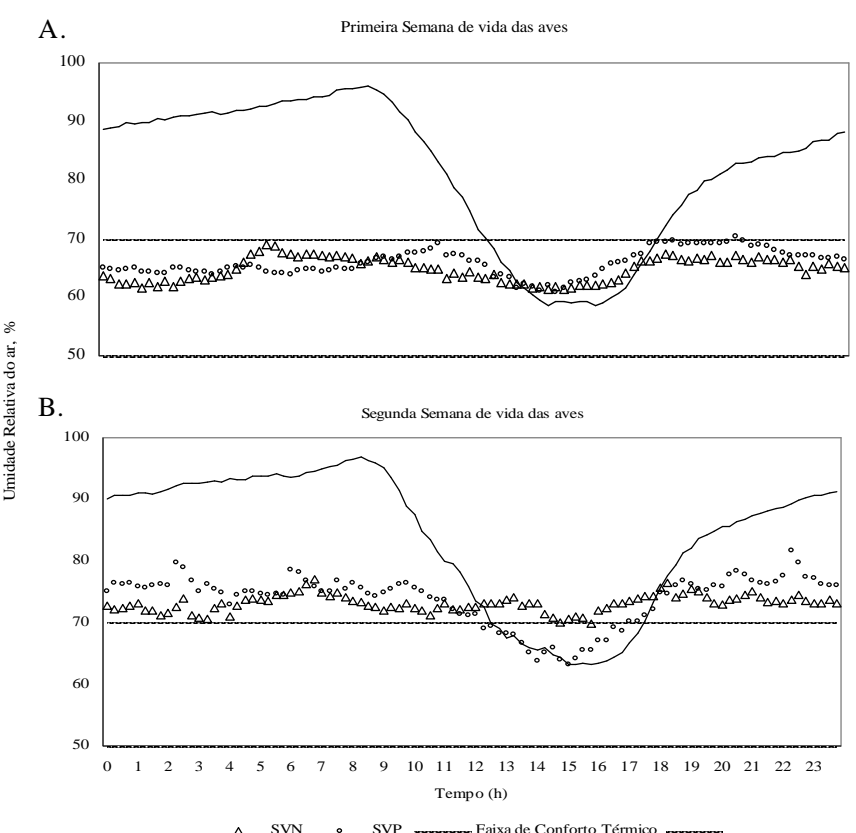

Figura 2. M édias da umidade relativa do ar (UR), no ambiente interno e externo, em função dos horários, para a primeira semana de vida das aves (A), e para a segunda semana de vida das aves (B), correspondentes aos tratamentos com Sistema de ventilação com pressão negativa (SVN) e positiva (SVP)

De forma geral, os valores de UR estiveram entre 60 e $70 \%$ para ambos os tratamentos, com os menores valores ocorrendo em torno das $14 \mathrm{~h}$, as médias gerais da primeira semana foram 64,7 e $65,8 \%$, para os tratamentos SVN e SVP, respectivamente (Figura $2 \mathrm{~A})$.

Com base nas curvas observadas na Figura 2B, verifica-se que os tratamentos SVN e SVP apresentaram os valores mínimos observados de umidade relativa nos horários das 15 h, com 69,9 e 63,2\% respectivamente, indicando condições favoráveis de UR para as aves, na segunda semana de vida.

Observa-se, na Figura 2A e B, que os valores médios de UR do ar no ambiente externo circunvizinho às instalações em análise foram muito superiores aos obtidos para os dois tratamentos no ambiente interno, com os maiores valores pela manhã, decrescendo até aproximadamente $14 \mathrm{~h}$ e crescendo novamente aproximadamente a partir das $17 \mathrm{~h}$; no interior das instalações as curvas de UR observadas indicaram as mesmas tendências ao comportamento externo, porém com a vantagem de um ambiente protegido e controlado pela instalação, apresentado níveis confortáveis para o bom desenvolvimento das aves.

De acordo com Tinôco (2001), a umidade relativa do ar interior de uma instalação avícola deve permanecer em torno de 50 a $70 \%$, esses valores de umidade relativa são favoráveis para manter boa qualidade de cama sem que se torne muito seca ou empoeirada.

A Figura 3 apresenta os resultados médios de ITGU no ambiente interno, referentes às primeira e segunda semanas de vida das aves, correspondentes aos dois tratamentos de ventilação higiênica do ar no período de aquecimento, SVN e SVP.

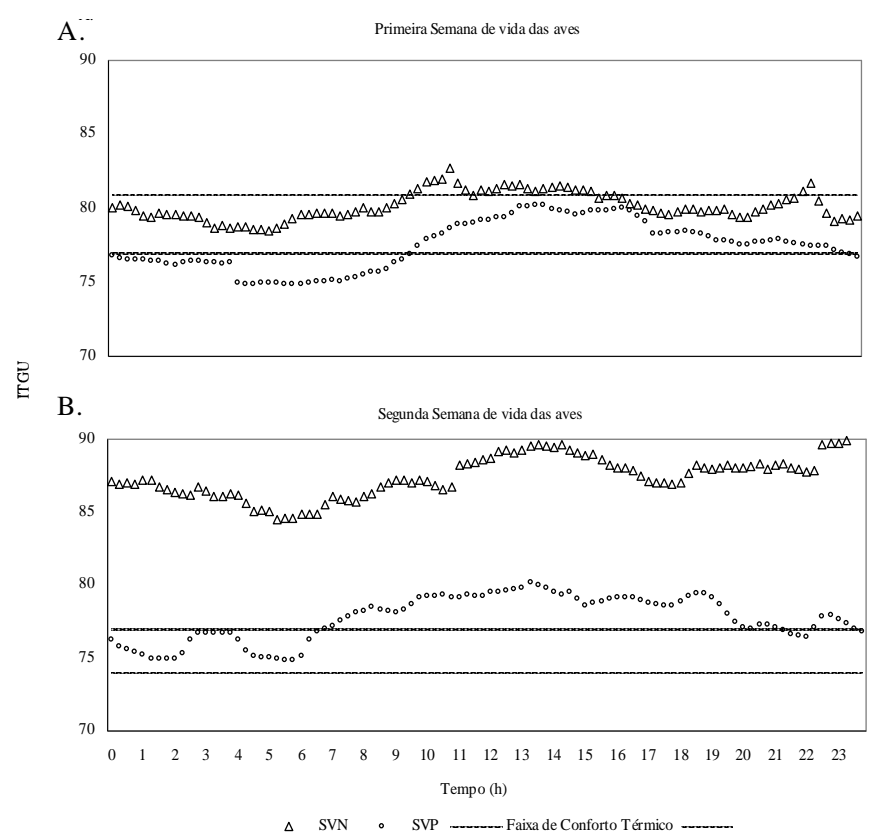

Figura 3. M édias do índice de temperatura de globo negro e umidade (ITGU), no ambiente interno, em função dos horários na primeira semana de vida das aves (A) e na segunda semana de vida das aves (B), correspondentes aos tratamentos com Sistema de ventilação com pressão negativa (SVN) e positiva (SVP)

Verifica-se, em todos os horários, que os valores de ITGU foram maiores no tratamento SVN, para as duas primeiras semanas de vida das aves devido, provavelmente, ao maior número de aves alojadas por unidade de área $\left(40,8\right.$ aves $\mathrm{m}^{-2}$ na segunda semana de vida das aves) no aviário ventilado com pressão negativa em relação ao ventilado por pressão positiva (29,4 aves $\mathrm{m}^{-2}$ na segunda semana de vida das aves). Maior quantidade de aves resultou em maior quantidade de calor dissipada pelos animais e maior carga térmica advinda da cobertura dessa instalação (chapas de zinco) o que afeta diretamente a temperatura de globo negro, variável importante deste índice.

Segundo Oliveira et al. (2006), valores variando entre 81,3 e 77 de 1 a 7 dias de idade, correspondentes à fase de aquecimento para frangos de corte, indicam condições de conforto. Na maioria dos horários durante a primeira semana de vida das aves, para ambas as instalações o ITGU apresentou condições de conforto térmico ambiente (Figura 3A). Conforme se observa na Figura 3B, na segunda semana para o tratamento SVN apresentaram-se valores médios superiores a 85 , na maioria dos horários, o que indica desconforto para as aves, e assim, segundo Oliveira et al. (2006) a faixa indicativa de conforto térmico para a segunda semana de vida das aves compreende-se entre valores de 77 e 74,5 .

Observa-se, ainda, que as curvas de ITGU na fase de aquecimento para os sistemas analisados em função das horas do dia, apresentaram tendências semelhantes de comportamento. Os valores médios de ITGU se mostraram sempre superiores para o SVN, com as maiores amplitudes na segunda semana de vida das aves (7 a 14 dias) e nos horários entre 13 e $16 \mathrm{~h}$. Comportamento semelhante também foi encontrado por outros autores (Santos et al., 2002; Ti- 
nôco et al., 2004), cujos valores máximos estavam entre 12 e 16 h (Figura 3A e B).

Ressalta-se que os tratamentos em estudo possuíam densidades de alojamento diferenciadas, em que o SVN tinha maior número de aves alojadas por $\mathrm{m}^{2}$; no entanto, existe a possibilidade de se atribuir, a este fato, o aumento na dissipação de calor para o ambiente, resultante da ação dos mecanismos fisiológicos da ave para manutenção de sua homeotermia, manifestando condições desconfortáveis ao ambiente térmico.

\section{Concentrações de gases}

Verifica-se na Tabela 2, os valores médios da concentração de gases, monóxido de carbono $\left(\mathrm{CO}_{2}\right)$ e dióxido de carbono $(\mathrm{CO})$, em relação aos períodos observados, para ambos os sistemas de criação.

Tabela 2. Médias* de concentração de monóxido de carbono (CO) e dióxido de carbono $\left(\mathrm{CO}_{2}\right)$, em ppm, nos tratamentos com sistema de ventilação com pressão negativa (SVN) e positiva (SVP)

\begin{tabular}{ccccc}
\hline \multirow{2}{*}{ Tratamentos } & \multicolumn{2}{c}{$\mathbf{C O}$ (ppm) } & \multicolumn{2}{c}{$\mathbf{C O}_{\mathbf{2}}$ (ppm) } \\
\cline { 2 - 5 } & $\mathbf{9} \mathbf{h}$ & $\mathbf{1 5} \mathbf{~}$ & $\mathbf{9} \mathbf{~}$ & $\mathbf{1 5} \mathbf{~ h}$ \\
SVN & $8,79 \mathrm{aA}$ & $3,93 \mathrm{aA}$ & $1964,7 \mathrm{aA}$ & $1602,3 \mathrm{bA}$ \\
SVP & $2,65 \mathrm{aB}$ & $1,87 \mathrm{aA}$ & $2377,9 \mathrm{aA}$ & $2090,3 \mathrm{bA}$ \\
\hline
\end{tabular}

*As médias seguidas de pelo mesma letra minúscula na linha (horários) e maiúscula na coluna (tratamentos) não diferem entre si a nível de $5 \%$ de probabilidade pelo teste de Tukey

Para a concentração de dióxido de carbono não houve diferença estatística entre os tratamentos SVN e SVP, nos dois horários observados ( 9 e 15 h). Os valores de dióxido de carbono encontrados nos dois tratamentos estão dentro dos limites aceitáveis para instalações avícolas uma vez que se recomenda o limite de 3.000 ppm como o máximo para exposição contínua dos animais nas instalações (Wathes, 1999; Nääs et al., 2007); contudo, notou-se diferença estatística em ambas as instalações em relação aos horários analisados, verificando-se valores mais altos de concentrações de $\mathrm{CO}_{2}$ no horário de $9 \mathrm{~h}$, devido as instalações não terem sofrido manejo de abertura de cortinas durante a noite e nas primeiras horas do dia em razão das baixas temperaturas. No tempo de $15 \mathrm{~h}$, em ambas as instalações houve manejo de abertura de cortinas conforme a necessidade e também pela maior movimentação dos tratadores promovendo abertura de portas promovendo assim, a renovação do ar interno das instalações.

Observa-se na Tabela 2, que não houve diferença estatística entre os valores de CO registrados com relação aos horários, para os dois tratamentos, porém há diferença estatística para as concentrações de $\mathrm{CO}$ entre os tratamentos no período da manhã (9 h), em que o SVN apresentou as maiores concentrações.

Nääs et al. (2007) observaram em pesquisas com frangos de corte em períodos frios, valores de 30 ppm (em sistema de ventilação tipo túnel) e 18 ppm (com ventilação convencional) na fase de aquecimento acima, portanto, dos $10 \mathrm{ppm}$ máximos recomendados por Wathes (1999); os valores encontrados nos dois tratamentos SVN e SVP estiveram dentro de uma faixa considerada de segurança, com valor médio máximo de 8,79 ppm encontrados no SVP, permitindo concluir que este fator não representou risco à saúde das aves alojadas em ambos os tratamentos. Mas se observa, que os níveis gasosos maiores pela manhã devem estar associados ao fato de se ter mantido os galpões fechados durante o período noturno; entretanto, nos dias mais frios, visando manter o aquecimento desejado no interior das instalações, as operações de manejo, como abertura de cortinas laterais no SVP e uso de exaustor no SVN, utilizado para a renovação mínima higiênica da massa de ar do ambiente interno dos aviários, geralmente foram realizadas após a coleta de dados das concentrações gasosas indicando, então, as piores condições de qualidade do ar.

\section{CONCLUSÕES}

1. Conclui-se que a temperatura média do ar não correspondeu àquela considerada de conforto térmico para as aves, em virtude de falhas no fechamento das instalações e no aquecimento.

2. Em relação à umidade relativa do ar, ambos os tratamentos apresentaram níveis satisfatórios para um bom desenvolvimento do plantel.

3. O índice de temperatura de globo negro e umidade (ITGU) indicaram as melhores condições de conforto térmico ambiente na primeira semana de vida das aves para o tratamento com Sistema de ventilação com pressão positiva (SVP) sendo que, na segunda semana, apontou condições desfavoráveis de conforto térmico para ambos os sistemas.

4. As concentrações de monóxido e dióxido de carbono não apresentaram valores prejudiciais para o sistema de ventilação com pressão negativa (SVN) e positiva (SVP), ou seja, permaneceram dentro dos limites aceitáveis de qualidade do ar, tanto no período da manhã quanto no da tarde.

\section{AGRADECIMENTOS}

À Universidade Federal de Viçosa; à empresa Perdigão Agroindustrial S.A., pela oportunidade e apoio técnico durante a realização da pesquisa, e à CAPES, pela concessão da bolsa de estudos.

\section{LITERATURA CITADA}

Alencar, M. C. B.; Nääs, I. de A.; Gontijo, L. A. Respiratory risks in broiler production workers. Revista Brasileira de Ciência Avícola, v.6, n.1, p.23-29, 2004.

Buffington, C. S.; Collazo-Arocho, A.; Canton, G. H.; Pitt, D.; Thatcher, W. W.; Collier, R. J. Black globe humidity index (BGHI) as comfort equation for dairy cows. Transactions of the ASAE, v.24, n.3, p.711-714, 1981.

Moura, D. J. de. Ambiência na produção de aves em clima tropical. Piracicaba: Iran José Oliveira da Silva, 2001. p.75-149.

Nääs, I. de A.; Miragliotta, M. Y.; Aradas, M. E. C.; Silva, I. J. O.; Baracho, M. dos S. Ambiência na produção de aves em clima Tropical. Piracicaba: FUNEP, 2001. v.1. 200p.

Nääs, I. de A.; Miragliotta, M.Y.; Baracho, M. dos S.; Moura, D. J. de. Ambiência aérea em alojamento de frangos de corte: poeira e gases. Engenharia Agrícola, v.27, n.2, p.326-335, 2007. 
Oliveira, R. F. M.; Donzele, J. L.; Abreu, M. L. T.; Ferreira, R. A.; Vaz, R. G. M. V.; Cella, P. S. Efeitos da temperatura e da umidade relativa sobre o desempenho e o rendimento de cortes nobres de frangos de corte de 1 a 49 dias de idade. Revista Brasileira de Zootecnia, v.35, n.3, p.797-803, 2006.

Owada, A. N.; Nääs, I. de A.; Moura, D. J. de; Baracho, M. dos S. Estimativa de bem-estar de frango de corte em função da concentração de amônia e grau de luminosidade no galpão de produção. Engenharia Agrícola, v.27, n.3, p.611-618, 2007.

Reece, F. N.; Lott, B. D.; Deaton, J. W. Ammonia in the atmosphere during brooding affect performance of broiler chikens. Poultry Science, v.59, n.1, p.486-488, 1980.

Ronchi, C. Principais práticas de manejo para aves recém nascidas. Revista Aveworld, ano 1, n.6, p.26-30, 2004.

Santos, R. C.; Tinôco, I. de F. F.; Paula, M. O. de; Cordeiro, M. B.; Silva, J. N.da. Análise de coberturas com telhas de barro e alumínio, utilizadas em instalações animais para duas distintas alturas de pé-direito. Revista Brasileira de Engenharia Agrícola e Ambiental, v.6, n.1, p.142-146, 2002.
Silva, A.; Nääs, I. de A. Equipamentos para aquecimento e refrigeração. Produção de frangos de corte. Mendes, A. A.; Nääs, I. de A.; Macari, M. (ed.). Campinas: FACTA, 2004. $356 \mathrm{p}$.

Tinôco, I. de F. F. Avicultura industrial: Novos conceitos de materiais, concepções e técnicas construtivas disponíveis para galpões avícolas brasileiros. Revista Brasileira de Ciência Avícola, v.3, n.1, p.1-26, 2001.

Tinôco, I. de F. F.; Figueiredo, J. L. A.; Santos, R. C.; Silva, J. N. da; Pugliesi, N. L. Placas porosas utilizadas em sistemas de resfriamento evaporativo. Engenharia na Agricultura, v.12, n.1, p.17-23, 2004.

UBA - União Brasileira de Avicultura. Relatório anual 2007/ 2008.http://www.uba.org.br/uba_rel08_internet.pdf. 29 Set. 2008.

Wathes, C. M. Strive for clean air in your poultry house. World Poultry, v.15, n.3, p.17-19, 1999. 